\title{
PRE-PAID SMART WATER OVER CLOUD COMPUTING AND WIRELESS SENSOR NETWORK
}

\author{
Kavyashree S \\ Master of Computer Applications, Jain University, Bangalore, India
}

Article DOI: https://doi.org/10.36713/epra4300

\begin{abstract}
Water is one of the most vulnerable non-renewable energy which needs immediate from all the sectors of society like an academy, research and from the industry. The deep literature study concludes that $70 \%$ of the earth is covered with water bodies that infect the human body made of $75 \%$ of water. Water is an integral part of everyone's daily life. Hence these water resources have to be invested wary consciously so that the upcoming generation could survive. The report produced by the World Health Organization (WHO) on India says that the inadequate water management system is a root cause for water scare city though India is well occupied with water bodies. Hence, in this paper, we motivate to propose an efficient water management system (WMS) based on wireless sensor networks and cloud computing. Here, we propose a Prepaid Water Distribution Scheme (PWDS) for the efficient utilization of water resources within the domestic environment. Implementation and validation show promising paradigm towards efficient water utilization.
\end{abstract}

KEYWORDS: World Health Organization (WHO), Water Management System (WMS), Prepaid Water Distribution scheme (PWDS)

\section{INTRODUCTION}

Water is one of the most valuable nonrenewable energy but nowadays water is going to be scary in the world. $70 \%$ of the earth is covered with water bodies, in fact, the human body itself is made up of $75 \%$ of water. The major percentage of water is salty i.e. $99 \%$ and the remaining $1 \%$ is available in the form of normal water. This available $1 \%$ of water again fluctuating based on several factors like rainfall, climates changes which affect the water level of various natural reservoirs like pond, river, and lakes. In the process of dealing with this problem, we have proposed a new model called the Pre-paid Water Distribution (PWD) approach which is based on IoT (Internet of Things) and cloud technology. Fig.1 illustrates the various approaches to smart water.

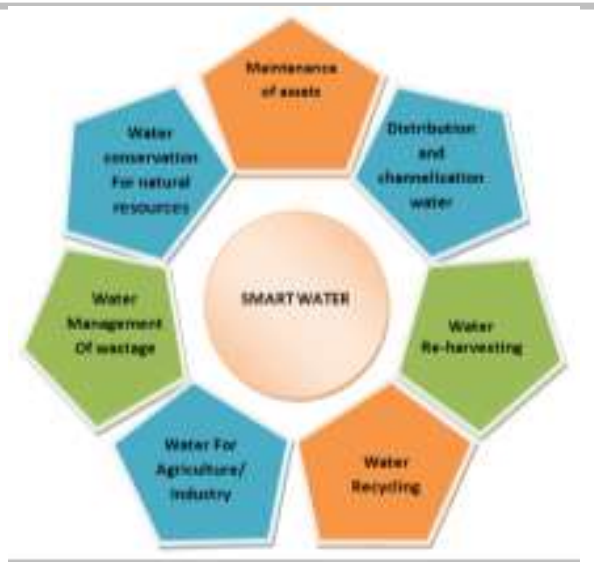

Fig.1 Smart Water Approaches

Advanced technology has become the integral part of our life [1]. To satisfy the need of the society, almost in each work, we use the technology [2] [3]. In current era computer science is major subject [4]. It has many real life applications such as cloud computing [5], artificial intelligence [6], remote monitoring [7], internet of things $[8,9,10,11,12,13,14,15]$, SPP $[16,17$, $18,19,20,21,22,23]$, TP $[24,25,26]$, internet 


\section{SJIF Impact Factor: 6.260| ISI I.F.Value:1.241| Journal DOI: 10.36713/epra2016 ISSN: 2455-7838(Online) \\ EPRA International Journal of Research and Development (IJRD) \\ Volume: 5 | Issue: 4 | April 2020 \\ - Peer Reviewed Journal}

Security [27], uncertainty [28, 29, 30] and so on. Technology is the mode by which user can store, fetch, communicate and utilize the information [31]. So, all the organizations, industries and also every individual are using computer systems to preserve and share the information. The internet security plays a major role in all computer related applications. The internet security appears in many real-life applications, e.g., home security, banking system, education sector, defense system, Railway, and so on. In this manuscript we discuss about the protection of authentication which is a part of internet security.

The IoT technology helps to setup a network of heterogeneous elements whereas cloud helps to store the end-user data in a centralized pattern. At present we have a smart water meter where it will calculate the usage of water of particular houses/apartment /building, but there is no proper maintenance of data of the user, so there are some disadvantages like cost, wastage of water, sometimes water meter may not work, etc. In the proposed system, we are using prepaid smart water systems on the cloud so that, data of the user will be stored in the cloud, so that it can be accessed anywhere anytime by anybody, and also there will be proper maintenance of data /information. These data can be used for saving water through proper water management because of every water drop matters. The following benefits that can be expected from the proposed system are: Effective utilization of water, Precise consumer information for billing and other managerial tasks, No wastage of water through proper conservation

Water is one of the basic needs required by everyone, water is an essential nutrient for the human body, animals and also plants, etc. We can survive up to several weeks without food but we can't survive without water so water plays an important role. Most of the living organisms depend on surviving, break down food, respiration process, regulate metabolism and dissolves compounds going into or out of the body. The water is also used in a domestic environment for many purposes like; water for drinking, bathing, cleaning cloths, food preparation, gardening, agriculture, and etc. The other outdoor uses are agriculture, industry, petroleum refineries, etc. In all these scenarios water resource is one of the most vulnerable energy. For Instance, if the agriculture field already

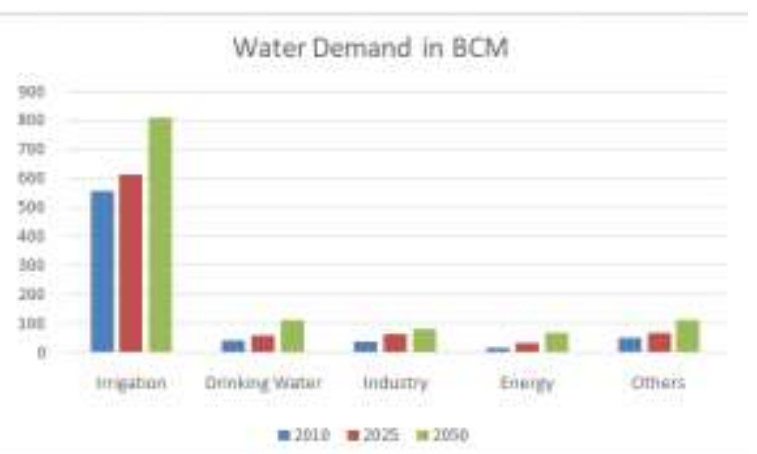

Fig 2: Statistical representation of Table 1

contains moistures then an additional watering process leads to wastage of water. The same way, in the Industrial sector miss management of water resources, may lead to actuate water shortage for other sectors of society. In Table 1, the demands of water by several sectors is presented.

\begin{tabular}{l|l|l|l|} 
Sector & Water Demand in BCM & & \\
& 2010 & 2025 & 2050 \\
\hline Irrigation & $\mathbf{5 5 7}$ & 611 & 807 \\
\hline Drinking Water & $\mathbf{4 3}$ & 62 & 111 \\
\hline Industry & 37 & 67 & 81 \\
\hline Energy & 19 & 33 & 70 \\
\hline Others & $\mathbf{5 4}$ & 70 & 111 \\
\hline Total & 710 & $\mathbf{8 4 3}$ & 1180
\end{tabular}

Table 1: Water demands by various sector

This subsection explores, the various well knew ongoing water projects all over the world [9]. "The First Resilient Kerala Program Development Policy Operation" (Kerala, India): This program improvises the strength of the state against natural calamities and climate change due to flood. [32] "Ceara Rural Sustainable Development and Competitiveness Phase II" (Brazil): This program improvises access to the markets, access to water \& sanitation, and adopting climate-resilient approaches by targeted beneficiaries in selected areas of Ciara [33] "Development Policy Financing with a Catastrophe Deferred Drawdown Option and Pandemic Emergency Financing Facility" (Maldives): This program improvises Maldives economic growth to manage the human physical and fiscal impact of climate changes, natural calamities, and disease outbreaks "Climate Resilience Multi-Phase Programmatic Approach" (Sri Lanka): This program improvises the functioning of the disaster management center (DMC). [34] "Vietnam - Dynamic Cities Integrated Development Project" (Vietnam): This program improvises access to urban infrastructure to 


\section{SJIF Impact Factor: 6.260| ISI I.F.Value:1.241| Journal DOI: 10.36713/epra2016 ISSN: 2455-7838(Online) \\ EPRA International Journal of Research and Development (IJRD) \\ Volume: 5 | Issue: 4 | April 2020 \\ - Peer Reviewed Journal}

improve integrated urban planning in the project cities. [35] "Karachi Water and Sewerage Services Improvement Project" (KWSSIP) (Pakistan): This program improvises for water services in Karachi and to enhance KWSB's economic and operational performance. [36] "Water Supply and Sanitation Improvement Project" (Cambodia): This program improvises to piped water supply and improved sanitation / domestic services and strengthens the operational performance of service providers in chosen towns and communes [37] "Modernization of Water Supply and Sanitation Services" (Peru): This program improvises the quality of water and domestic services in chosen areas and improve the Borrower's sectoral institutions and participating

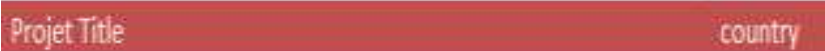

The First Resilient Kerala Program Development Policy Operation India
Ceara Rural Sustainable Development and Competitiveness Phase II Brazil

Climate Resilience Multi-Phase Programmatic Approach

Srilanka

Vietnam - Dynamic Cities Integrated Development Project

Karachi Water and Sewerage Services Improvement Project

Water Supply and Sanitation Improvement Project

Modemization of Water Supply and Sanitation Services

Urban Water Supply and Sanitation Project

Rural Water Supply and Sanitation Project

Development Policy Financing with a Catastrophe Deferred

Drawdown Option and Pandemic Emergency Financing Facility service providers' management capacity to provide efficient water and domestic services [38] "Urban Water Supply and Sanitation Project" (Cote d'Ivoire): This program improvises the quality and enhances the water services in chosen areas and strengthen the capacity of ONEP for economic planning and management of urban water supply sector [39] "Rural Water Supply and Sanitation Project" (Tajikistan): This program improvises the basic water supply and domestic services in chosen districts and strengthens the capacity of the institution in the water supply and sanitation sector [40] [41].

\section{Table2: History of ongoing water projects [9]}

Motivation: In this current work, we have explored a cloud-based pre-paid smart water management system to efficiently manages the water supply. The presence of cloud technology helps to create a centralized system for efficient data management about water consumption. The proposed pre-paid water scheme to supply a certain amount of water for a particular user based on their requests. Through this, we can reduce the wastage of water. The rest of the paper can be viewed as; Section 2: contains literature review; Section 3: explains proposed work, Section 4: discusses the result and discussion and Section 5: covers conclusion followed by references.

\section{LITERATURE REVIEW}

In this paper, the author designed water management using IoT so this paper tells about the water level monitor continuously from anywhere using an android application. It is a robust system and small in size. But this application is implemented in bungalow or Industrial level in further added feature can deploy IoT devices in the sea, leak, and river so if any varies in water level the user can get the notification for alerting [42]. In this paper, the author presenting a practical lowcost smart water meter device which is capable of determining possible leakage in the customer's property and reporting current household water consumption levels in real-time in this we can only detect so further added feature is to build any android application so that user can access their data anywhere any time [43]. In this paper, the author implemented a smart water quality monitoring system. This paper deals with checking the quality of water in certain areas based on the temperature relation with $\mathrm{ph}$. The conductivity factor also has been observed for all the water samples using GSM Technology. It is an added feature of incorporating IoT Platform for real-time water monitoring [44]. In this paper, the authors has been deployed an efficient and cost effective method of placing an upper limit on the amount of water used on daily basis. So, incase water level 


\section{SJIF Impact Factor: 6.260| ISI I.F.Value:1.241| Journal DOI: 10.36713/epra2016 ISSN: 2455-7838(Online) EPRA International Journal of Research and Development (IJRD) Volume: 5 | Issue: 4 | April 2020

raised then user is pre-alarmed and the proposed design in a strategy, which will also help the user to keep a check on the amount of water leaking from the faucet. This work is promoting smart planning for health and sustainable water management [45].

This paper focuses on the interfaces and leakages between formal and informal institutional frameworks for water management. There is a case study on the same can be viewed at Tanzania, Mkoji sub-catchment in the Rufiji Basin [46]. In this paper, the author has presented, the architecture for the smart water distribution system (SWDS) that cooperate with the IoT and Cloud Computing and ICT Technologies. This architecture is designed for intermittent water supply while the previous works is for continuous water supply [47]. In this paper, the author has discussed, some of the key challenges for smart water. In order to, overcome the water shortage problems some steps had been carried out like the development of resources, reduction of higher demands, efficiency in treatment and transmission, etc. [48]. This study has especially donated to the scientific community inside the below-stated areas; Understanding contribution in how we consume water in our homes. A paperback study makes use of real-life information from rental apartments. Indicate that the EDA method is a strong approach when no beforehand secure expectation is held and well suited for this type of Investigative studies. How smart meter data can potentially benefit stakeholders at a building level and improve water management. A good example of an integrated and interdisciplinary approach to tackle composite challenges. Another future research area is the execution of data-driven decision making and management based on smart meter data [49].

In This paper author represents the existing and proposed smart water system and network communication identification, customers who are installed utility meter application based on that amount will be calculated and in this paper researched some of the challenges faced when creating scalable smart water meter networks [50]. In this paper author represents the smart water development and also analysis the current key problems of water information like construction is not proper, data resources need to be integrated, business collaboration and the entire framework of particular area smart water designed and finally this paper represents the architecture of regional smart water by using "Internet of things and also cloud computing [51]. In this paper author represents the novel system for implementing an financial and reliable smart water distributing metering using IoT and smartphone application, the work is being extended to cover a range of distribution metering and lacking for water issues faced by utility centers while providing direct and intangible gains to consumers. And changing the infrastructure of smart water [52].

In this paper, the author represents the architecture and implementation of a smart home irrigation system. The system consists of two sensors motes, special soil humidity sensors, and java application is used for data collection, It also proved that the system is aware of the different watering needs for future work and all the work is managed remotely [53]. In this paper author represents the developments of a small-scale testbed, water box, that simulates smart water networks and also active the evaluation of in-node decision making, energy optimization, automatic control, and event-driven communication algorithms, And also they worked for applying more complex algorithms including new scenarios like security and new sensors such as Water quality [54].In this paper author represents a monitoring system based on user-defined rules for checking resources consumption and co-ordination in community domains, as future work, they decided to design a greater interaction between the monitoring system, home automation control system so that the execution of rules allow actions on the devices such as blocking, putting in low consumption [55]. In this paper, the author represents smart water sensor can developed by ' $n$ Instituto Technologic de Galicia (ITG), for monitoring water quality in remote place infrastructure is made up of hardware unit and web platform it supports sample measurement, local storage, power source, remote control, platform storage, and graphical representation in a web platform. the main advantage of developed station is versatility [56]

\section{PROPOSED SYSTEM}

The could computing plays an important role in all over the world because it facilitates the user with more benefits like cost reduction by providing some of the services like software as a service, infrastructure as a service, platform as a service, it central remote servers to maintain data and applications and could computing allows consumers and business to use applications without installation and provide storage facilities with security benefits, with low cost and can access anywhere by using the internet so most of the small business as well big one depends on cloud. By using the cloud enables users to get their applications to market easily if in the case of hardware failure does not affect the data, because of network backups cloud computing uses remote 


\section{EPRA International Journal of Research and Development (IJRD)

resources. Saving organizations, the cost of servers and other equipment.

In this paper, the cloud plays an import role because it will store the data of the particular user, information of utility center, and also record the use of water by particular houses so there will be a proper record of each and every user, they can access their data anywhere any time by using the internet and all the areas data will be integrated in the cloud so no need of physical servers required to store the data, it will help the organization with reduction of cost and wastage of water.

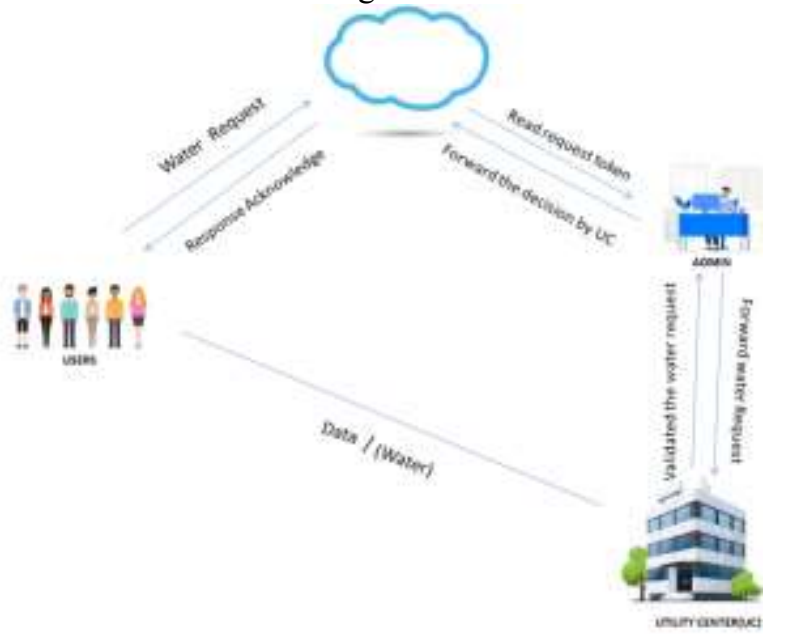

Fig 3: Architecture of Proposed System

\section{FORMULATION}

Input: Sensor Nodes, Base Station, Mobile Sensors

Output: Water Distribution

Step 1: Initialization sensor Nodes with request to the cloud

Step 2: Forward: cloud will forward these to utility center

Step 3: If, Water (Amount_REQ) < (AVL Quantity)

Step 4: Acknowledgement from Admin

Step 5: Confirmation from User

Step 6: Admin send the request to Utility center to provide particular quantity of water to user

Step 7: Distribute water from utility center to user

\section{DEPLOYMENT}

For Deployment used Cup carbon software:

Stages of deployment:

Step 1: login to cup carbon-> First save the file in cupcarbon

Step 2: Deploy the sensor in map

Step 3: Deploy 8 server sensor node

Step 4: Deploy 2 mobile sensor

Step 5: Deploy 2 Base station

Step 6: Connect everything in one network

Server sensor node: A sensor node is an object that can detect any digital event (motion event like mobiles), send and receive data. It can be also mobile. The visible parameters of a sensor node are: the radio range, the radio of the sensor unit and the name. 


\section{EPRA International Journal of Research and Development (IJRD) \\ Volume: 5 | Issue: 4 | April 2020 \\ - Peer Reviewed Journal}

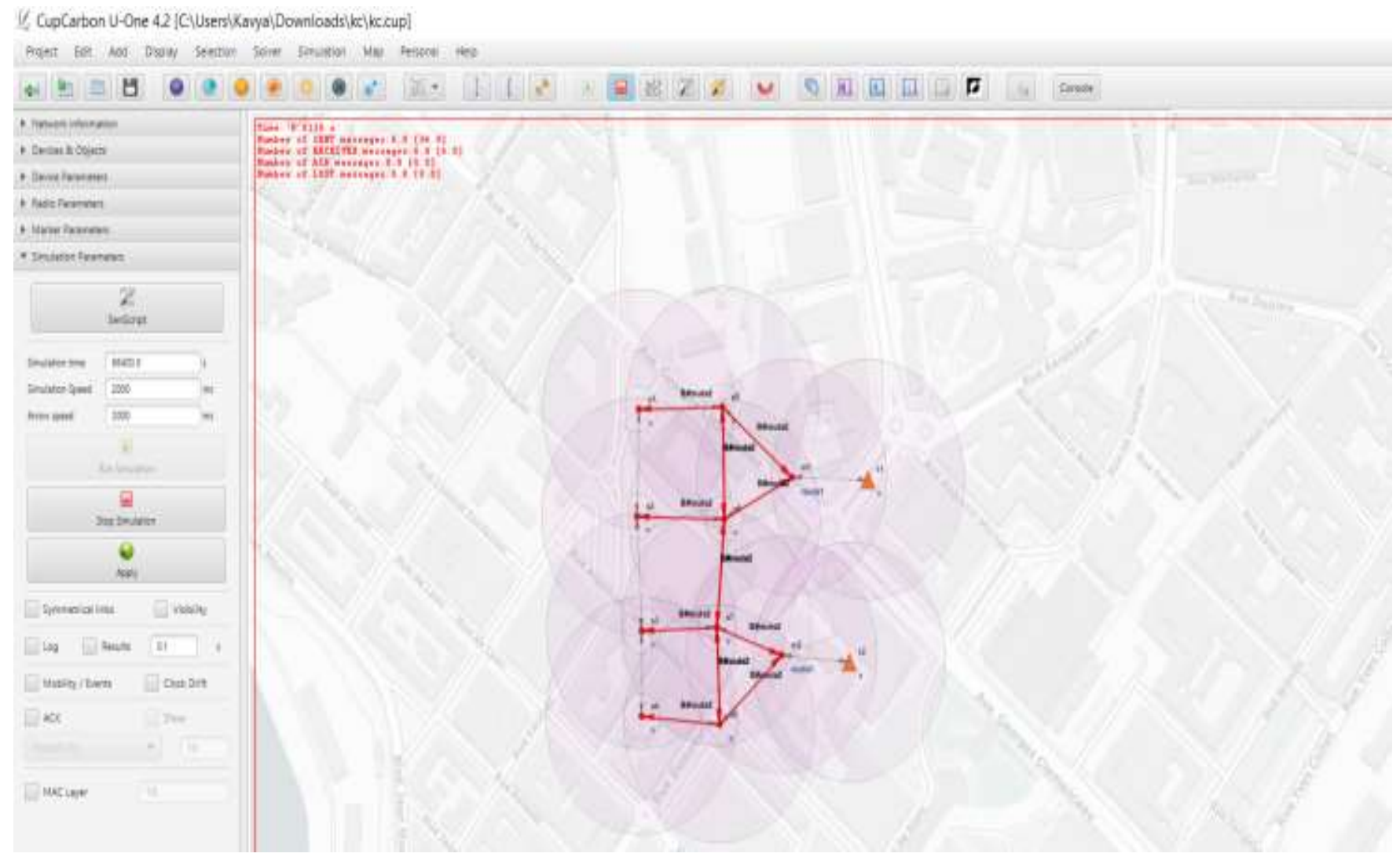

Fig. 5. Sensor Node Deployment

Mobile sensor: Mobile sensor node is used for direction the sensor nodes.

Base station: Base station is used for sinks more sensors in single network

Run Simulation: to start the simulation

Stop Simulation: to stop the simulation

Sen Script Window: to open the Sen Script window and write the script to sensors

Device parameters: Device parameters are used to

\section{DISCUSSION}

Above Fig 5 describe the deployment of sensor, where Server sensor represents the home/apartments and mobile sensor acts as mediator between houses and utility center to transform the requests from user to admin of utility center. where one base station acts as admin and one base station is utility center, here data is nothing but water and water will be distributed according to user request. The cloud plays an import role because it will store the Information of the particular user, utility center, and also record the use of water by particular houses so there will be a proper record of each and every user, they can access their data anywhere any time by using the internet and all the areas data will be integrated in the cloud.

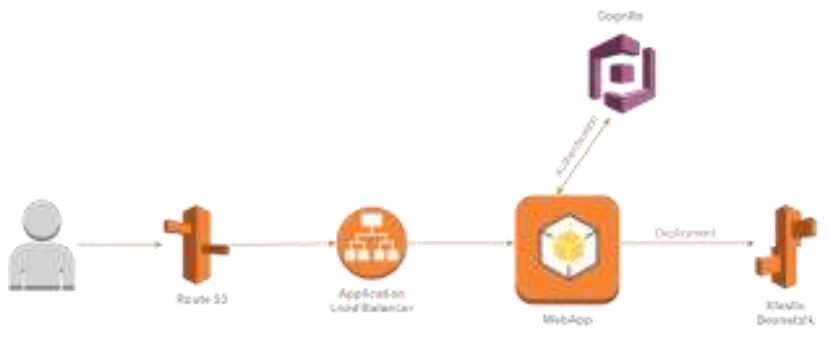

Fig 6: Work flow in Cloud 1 
SJIF Impact Factor: 6.260| ISI I.F.Value:1.241| Journal DOI: 10.36713/epra2016 ISSN: 2455-7838(Online)

\section{EPRA International Journal of Research and Development (IJRD)}

Volume: 5 | Issue: 4 | April 2020

- Peer Reviewed Journal

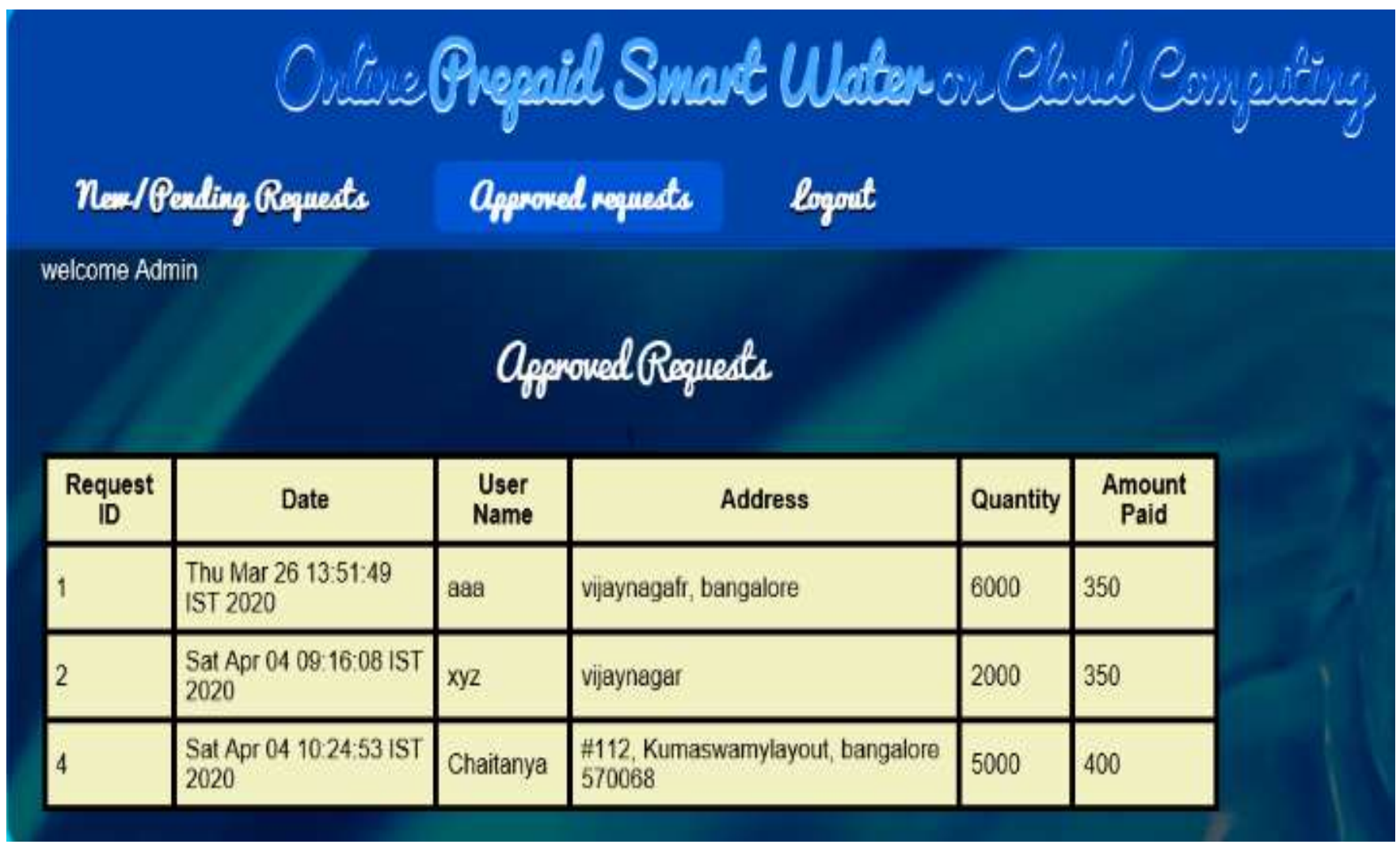

Fig 7. Console Management

The simulation results of prepaid smart water over cloud computing and wireless sensor network using different tools the parameters could decrease the wastage of water and maintain the proper data of the user. Proper distribution of water, cost effective, easy to maintain / access.

\section{CONCLUSIONS}

In this paper, we represented the architecture and implementation of prepaid smart water over cloud computing and wireless sensor network. The sensor consists of three sensor nodes(Server sensor node, Mobile sensor, base station) with the use of cupcarbon software and develops an application using java that is used for conversation between end-user and admin. Performance evaluation showed that our cloud manages the user data and maintain the record of consumption of water and calculate the quantity of water of particular user and also merge the particular area data and integrated with the cloud so utility center can easily manage the data of every user.

\section{REFERENCES}

[1] M. M. B and H. Mohapatra, "Human Centric Software Engineering," International Journal of Innovations \& Advancement in Computer Science (IJIACS), vol. 4, no. 7, pp. 86-95, 2015.

[2] H. Mohapatra, C Programming: Practice, Vols. ISBN: 1726820874, 9781726820875, Kindle, 2018.

[3] H. Mohapatra and A. Rath, Advancing Generation Z Employability through New Forms of Learning: quality assurance and recognition of alternative credentials, ResearchGate, 2020.

[4] H. Mohapatra and A. K. Rath, Fundamentals of Software Engineering: Designed to provide an insight into the software engineering concepts, $B P B, 2020$.

[5] V. K. Ande and H. Mohapatra, "SSO Mechanism in Distributed Environment," International Journal of Innovations \& Advancement in Computer Science, vol. 4, no. 6, pp. 133-136, 2015.

[6] H. Mohapatra, "Ground Level Survey on Sambalpur In the Perspective of Smart Water," EasyChair, vol. 1918, p. 6, 2019.

[7] H. Mohapatra, S. Panda, A. Rath, S. Edalatpanah and R. Kumar, "A tutorial on powershell pipeline and its loopholes," International Journal of Emerging Trends in Engineering Research, vol. 8, 


\section{SJIF Impact Factor: 6.260| ISI I.F.Value:1.241| Journal DOI: 10.36713/epra2016 ISSN: 2455-7838(Online) EPRA International Journal of Research and Development (IJRD)

no. 4, 2020.

[8] H. Mohapatra, "HCR using neural network," 2009.

[9] H. Mohapatra and A. Rath, "Detection and avoidance of water loss through municipality taps in india by using smart tap and ict," IET Wireless Sensor Systems, vol. 9, no. 6, pp. 447-457, 2019.

[10] H. Mohapatra and A. Rath, "Fault tolerance in WSN through PE-LEACH protocol," IET Wireless Sensor Systems, vol. 9, no. 6, pp. 358-365, 2019.

[11] H. Mohapatra, S. Debnath and A. Rath, "Energy management in wireless sensor network through EB-LEACH," International Journal of Research and Analytical Reviews (IJRAR), pp. 56-61, 2019.

[12] V. Nirgude, H. Mahapatra and S. Shivarkar, "Face recognition system using principal component analysis \& linear discriminant analysis method simultaneously with $3 d$ morphable model and neural network BPNN method," Global Journal of Advanced Engineering Technologies and Sciences, vol. 4, p. 1, 2017.

[13] M. Panda, P. Pradhan, H. Mohapatra and N. Barpanda, "Fault tolerant routing in heterogeneous environment," INTERNATIONAL JOURNAL OF SCIENTIFIC \& TECHNOLOGY RESEARCH, vol. 8, pp. 1009-1013, 2019.

[14] H. Mohapatra and A. Rath, "Fault-tolerant mechanism for wireless sensor network," IET Wireless Sensor Systems, vol. 10, no. 1, pp. 23-30, 2020.

[15] D. Swain, G. Ramkrishna, H. Mahapatra, P. Patra and $P$. Dhandrao, "A novel sorting technique to sort elements in ascending order," International Journal of Engineering and Advanced Technology, vol. 3, pp. 212-126, 2013.

[16] S. Broumi, A. Dey, M. Talea, A. Bakali, F. Smarandache, D. Nagarajan, M. Lathamaheswari and $R$. Kumar, "Shortest path problem using Bellman algorithm under neutrosophic environment," Complex \& Intelligent Systems, vol. 5, pp. 409--416, 2019.

[17] R. Kumar, S. Edalatpanah, S. Jha, S. Broumi, R. Singh and A. Dey, "A multi objective programming approach to solve integer valued neutrosophic shortest path problems," Neutrosophic Sets and Systems, vol. 24, pp. 134-149, 2019.

[18] R. Kumar, A. Dey, F. Smarandache and S. Broumi, "A study of neutrosophic shortest path problem," in Neutrosophic Graph Theory and Algorithms, F. Smarandache and S. Broumi, Eds., IGI-Global, 2019, pp. 144-175.

[19] R. Kumar, S. Edalatpanah, S. Jha and R. Singh, "A novel approach to solve gaussian valued neutrosophic shortest path problems," International Journal of Engineering and Advanced Technology, vol. 8, pp. 347-353, 2019.

[20] R. Kumar, S. Edalatpanah, S. Jha, S. Gayen and R. Singh, "Shortest path problems using fuzzy weighted arc length," International Journal of Innovative Technology and Exploring Engineering, vol. 8, pp. 724-731, 2019.

[21] R. Kumar, S. Edaltpanah, S. Jha, S. Broumi and A. Dey, "Neutrosophic shortest path problem," Neutrosophic Sets and Systems, vol. 23, pp. 5-15, 2018.

[22] R. Kumar, S. Jha and R. Singh, "A different approach for solving the shortest path problem under mixed fuzzy environment," International Journal of fuzzy system Applications, vol. 9, no. 2, pp. 132-161, 2020.

[23] R. Kumar, S. Jha and R. Singh, "Shortest path problem in network with type-2 triangular fuzzy arc length," Journal of Applied Research on Industrial Engineering, vol. 4, pp. 1-7, 2017.

[24] R. Kumar, S. Edalatpanah, S. Jha and R. Singh, "A Pythagorean fuzzy approach to the transportation problem," Complex and Intelligent System, vol. 5, pp. 255-263, 2019.

[25] J. Pratihar, R. Kumar, A. Dey and S. Broumi, "Transportation problem in neutrosophic environment," in Neutrosophic Graph Theory and Algorithms, F. Smarandache and S. Broumi, Eds., IGI-Global, 2019, pp. 176-208.

[26] J. Pratihar, S. E. R. Kumar and A. Dey, "Modified Vogel's Approximation Method algorithm for transportation problem under uncertain environment," Complex \& Intelligent Systems (Communicated).

[27] J. Sakhnini, H. Karimipour, A. Dehghantanha, R. Parizi and G. Srivastava, "Security aspects of Internet of Things aided smart grids: A bibliometric survey, "Internet of Things, pp. 100-111, 2019.

[28] S. Gayen, F. Smarandache, S. Jha and R. Kumar, "Interval-valued neutrosophic subgroup based on interval-valued triple t-norm," in Neutrosophic Sets in Decision Analysis and Operations Research, M. Abdel-Basset and F. Smarandache, Eds., IGIGlobal, 2019, p. 300.

[29] S. Gayen, F. Smarandache, S. Jha, M. Singh, S. Broumi and R. Kumar, "Introduction to plithogenic subgroup," in Neutrosophic Graph Theory and Algoritm, F. Smarandache and S. Broumi, Eds., IGI-Global, 2020, pp. 209-233.

[30] S. Gayen, S. Jha, M. Singh and R. Kumar, "On a generalized notion of anti-fuzzy subgroup and some characterizations," International Journal of Engineering and Advanced Technology, vol. 8, pp. 385-390, 2019.

[31] A. Behura and H. Mohapatra, "IoT Based Smart City with Vehicular Safety Monitoring, " EasyChair, vol. 1535, 2019.

[32] The First Resilient Kerala Program Development Policy Operation, The World Bank, 2019.

[33] Ceara Rural Sustainable Development and Competitiveness Phase II, 2019. 


\section{SJIF Impact Factor: 6.260| ISI I.F.Value:1.241| Journal DOI: 10.36713/epra2016 ISSN: 2455-7838(Online) EPRA International Journal of Research and Development (IJRD) Volume: 5 | Issue: 4 | April 2020 \\ - Peer Reviewed Journal}

[34] Climate Resilience Multi-Phase Programmatic Approach, The World Bank, 2019.

[35] Vietnam: Dynamic Cities Integrated Developement Project, The World Bank, 2019.

[36] The World Bank, Karachi Water and Sewerage Services Improvement Project, 2019.

[37] The World Bank, Water Supply and Sanitation Improvement Project" (Cambodia):, 20119.

[38] The World Bank, Modernization of Water Supply and Sanitation Services" (Peru), 2019.

[39] The World Bank, "Urban Water Supply and Sanitation Project”, 2019.

[40] The World Bank, Rural Water Supply and Sanitation Project, 2019.

[41] The World Bank, Development Policy Financing with a Catastrophe Deferred Drawdown Option and Pandemic Emergency Financing Facility, 2019.

[42] SayaliWadekar, V. Vakare, R. Prajapati, S. Yadav and V. Yadav, "Smart Water Management Using IoT," in 5th International Conference on Wireless Networks and Embedded Systems, Rajpura, 2017.

[43] S. R. K. O. C. M. J. P. Bheki SITHOLE, "Smart water leakage detection and metering device," in IST-Africa Week Conference, Dubai, 2016.

[44] K. A. M. F. R. I. H. H. A.N.Prasad, "Smart Water Quality Monitoring System," in 2nd IEEE Asia Pacific World Congress on Computer Science and Engineering, Fiji, 2015.

[45] U. S. G. V. D. Prachi Dutta, "Faucet Add-On Water Supply Management System Using Smart Sensors," in 2016 Second International Conference on Computational Intelligence \& Communication Technology (CICT), 2016.

[46] W. M. a. B. v. K. Charles. S. Sokile, "Integrated Water Resource Management in Tanzania: Interface between Formal and Informal Institutions," in African Water Laws: Plural Legislative Frameworks for Rural Water, Johannesburg, 2005.

[47] S. K. Alshattnawi, "Smart Water Distribution Management System Architecture Based on Internet of Things and Cloud Computing," in International Conference on New Trends in Computing Sciences (ICTCS), 2017.
[48] P. Gourbesville, "Key Challenges For Smart Water," in International Conference on Hydroinformatics, 2016.

[49] P. D. ANNA SÖDERBERG, "Turning Smart Water Meter Data Into Useful Information," in INOM EXAMENSARBETE SAMHÄLLSBYGGNAD,AVANCERAD NIVÅ, STOCKHOLM, 2017.

[50] R. M. N. y. R. W. Jaco Marais, "A Review of the Topologies Used in Smart Water Meter Networks: A Wireless Sensor Network Application," hindawi, 2016.

[51] L. P. S. W. Y. X. Wang Yuanyuana, "A New Framework on Regional Smart Water," Science Direct.

[52] M. Suresh, U. Muthukumar and J. Chandapillai, "A Novel Smart Water-Meter based on IoT and Smartphone App for City Distribution Management," in IEEE Region 10 Symposium (TENSYMP), Cochin, 2017.

[53] M. M. M. G. M. A. E. A. A. R. A. A. A. A. S. Ahmed Hussein Abbas, "A Smart System for Garden Watering using Wireless Sensor Networks," in International Conference on Engineering and Technology (ICET), Cairo, 2014.

[54] E. A. J. A. M. SokratisKartakis, "WaterBox: A Testbed for Monitoring and Controlling Smart Water Networks," in CySWater'15 Proceedings of the 1st ACM International Workshop on CyberPhysical Systems for Smart Water Networks, 2015.

[55] B. B. D. M. D. S. d. R. Ramón Alcarria, "Rulebased Monitoring and Coordination of Resource Consumption in Smart Communities," in IEEE Transactions on Consumer Electronics, 2017.

[56] H. J. L. C. T. Marco A. González, "The ITG Smart Water Station," in 1st ACM International Workshop, 2015. 